\title{
Transformation of Saudi Arabia's Health System and Its Impact on Population Health: What Can the USA Learn?
}

\author{
Yuchi Young a Amani Alharthy $^{\mathrm{b}, \mathrm{c}}$ Akiko S. Hosler ${ }^{\mathrm{b}}$ \\ ${ }^{a}$ Department of Health Policy and Management, University at Albany School of Public Health, Rensselaer, NY, USA; \\ ${ }^{b}$ Department of Epidemiology and Biostatistics, University at Albany School of Public Health, Rensselaer, NY, USA; \\ 'Department of Epidemiology, College of Health and Rehabilitation Sciences, Princess Nourah Bint Abdulrahman \\ University, Riyadh, Saudi Arabia
}

\section{Keywords}

Saudi Arabia $\cdot$ Health system transformation - Six-part World Health Organization health system - Building blocks . Health outcomes - Universal healthcare

\begin{abstract}
Objective: The objective of this study was to describe the historic transformation of the Kingdom of Saudi Arabia (KSA) health system and analyze the impact of transformation on selected health outcomes in KSA. Methods: Secondary data from the following standard repositories were compiled for analysis: WHO, UN, UNICEF, and the Saudi Arabia Ministry of Health. The 6-part WHO health system framework was used to structure the analysis. The USA was chosen as a comparator country because KSA and the USA are both high-income OECD countries with predominantly Western-trained physicians and similar health outcomes, yet the 2 nations diverge in 2 important ways: the KSA is a single payer, and its percent GDP healthcare spending is one-half that of the USA. $\boldsymbol{R e}$ sults: Life expectancy at birth increased nearly 30 years (from 45.6 years in 1960 to 74.9 years in 2019) among KSA citizens, narrowing the gap with the USA, which gained 8.7 years, from 69.8 to 78.5 , during the same period. KSA had identical
\end{abstract}

infant mortality to the USA $(2 / 1,000$ live births in both countries) and lower maternal mortality rates (17 vs. $23 / 100,000$ live births) than the USA. Conclusion: The rapid improvement of selected health outcomes in KSA may be attributable to improved access to care provided by the universal healthcare system. Healthcare spending in the USA is $18 \%$ GDP, nearly twice that of KSA (9.2\% GDP), yet important health outcomes are largely indistinguishable. Future research should evaluate which elements of the KSA system might inform improvements to decentralized systems in the USA.

(c) 2021 The Author(s).

Published by S. Karger AG, Basel

\section{Introduction}

The Kingdom of Saudi Arabia (the KSA) is well known for its oil and gas reserves [1] and as the birthplace of Islam [2], but its achievements in improving health systems and population health may be underappreciated. English language literature on Saudi health systems and population health metrics is sparse; scarcer still are studies which provide meaningful comparisons with the USA. The KSA health system transformation in the past 6 decades is re-
(C) 2021 The Author(s)

Published by S. Karger AG, Basel

This is an Open Access article licensed under the Creative Commons Attribution-NonCommercial-4.0 International License (CC BY-NC) (http://www.karger.com/Services/OpenAccessLicense), applicable to the online version of the article only. Usage and distribution for commercial purposes requires written permission.
Correspondence to:

Yuchi Young, yyoung@albany.edu 
markable and brings great improvement in Saudi Arabia's population health. We use a comparative method to draw attention to similarities and differences in health systems and their impacts on selected health outcomes between the KSA and the USA using the WHO's 6 Health System building blocks as a framework for this comparison. Selected health outcomes for the comparisons include life expectancy at birth and at 65 and infant and maternal mortality rates. The USA is chosen for this comparison because higher GDP per capita spending is not always commensurate with better health outcomes; in addition to spending, the health system configuration and performance influence health outcomes. Given that the KSA has a national health care system, whereas the USA does not have national health insurance but a mixed health system operated by public and private organizations, the WHO's 6 building blocks offer standardized indicators that allow comparisons between countries. The 6 building blocks are service delivery, health workforce, health information system, access to medicines and technologies, health system financing, and leadership/governance.

Previous studies of health systems in the KSA mainly focus on an overview of the healthcare system [3], health information system [4], challenges in the healthcare services [5], and perceived medical services [6]. Almalki and associates [3] reviewed the historical development and current structure of the healthcare system in the KSA, considering the importance of the public health sector and the opportunities and challenges confronting the Saudi healthcare system. A similar study conducted by Walston et al. [5] highlighted challenges in the Saudi healthcare services, such as long wait times for nonemergency surgeries due to the increased demand for care coupled with construction delays as facilities struggle to expand capacity.

Two recent studies focus on the health information system [4] and access to care [6]. Albejaidi [4] examines the critical needs of a health information system in the KSA and reports the lack of an established and efficient National Health Information System (NHIS) as a likely cause of poor quality management in the Saudi health sector. The author concludes that there is an urgent need for improvement in the healthcare information system in the KSA to deal with the challenges created by an expanding health sector [4]. Another study carried out by Alsumaih and Aldhuwayhi [6] uses an online survey of Saudi students living in the USA to gather perceptions of medical service quality for comparison. The majority of Saudi students perceived medical services in the USA to be of higher quality than those provided in the KSA [6].

These studies have explored interesting facets of the Saudi health system, but to our knowledge, none has undertaken a comprehensive analysis of the longitudinal impact of massive health system transformation on selected health outcomes using established criteria. The objectives of this study are 3-fold: (1) describing the historic transformation of Saudi's health system in stages from a haphazard structure tailored to the needs of pilgrims to a well-coordinated modern system, (2) analyzing the impact of health systems on selected population health outcomes in the KSA and the USA using secondary data, and (3) systematically evaluating the longitudinal impact of these 2 health systems on selected health outcomes using the 6-factor WHO health system assessment criteria. The lessons learned from this study can be useful to the ongoing health system development in the KSA as well as in the USA.

\section{Methods}

Information related to the health system history in the KSA was obtained from the Saudi Ministry of Health $(\mathrm{MOH})$ website and a literature search using electronic databases (PubMed and Google Scholar) using the following keywords: health system, Saudi Arabia, United States, and comparison. The search was restricted to English literature, but no time restriction was placed on the publication date. To assess and compare the health systems' impact on selected population health indicators, we created charts and tables using the data abstracted from publications of the WHO, World Bank, UNICEF, and the Saudi MOH. Due to the limited availability of Saudi data, the comparative analysis study period was restricted to 1960-2019. Based on this literature review, a timeline was created with 5 stages to delineate the healthcare system evolution from 1925 to 2019 and beyond in the KSA. To answer the second research question, we evaluated the current state of Saudi health systems with respect to the following population health metrics: life expectancy and infant and maternal mortality. With respect to the third research question, we evaluated the evolution of the Saudi healthcare system according to the WHO 6 Building Blocks: service delivery, health workforce, health information system, access to medicines and technologies, health systems financing, and leadership and governance.

\section{Health Outcomes Definitions}

Definitions of population health outcomes used in this study are as follows.

\section{Life Expectancy}

The average number of years that a person could expect to live at birth if the person experiences the age-specific mortality rate prevalent in a specific country in a specific year. The data are adjusted for age, sex, and country [7].
Young/Alharthy/Hosler 


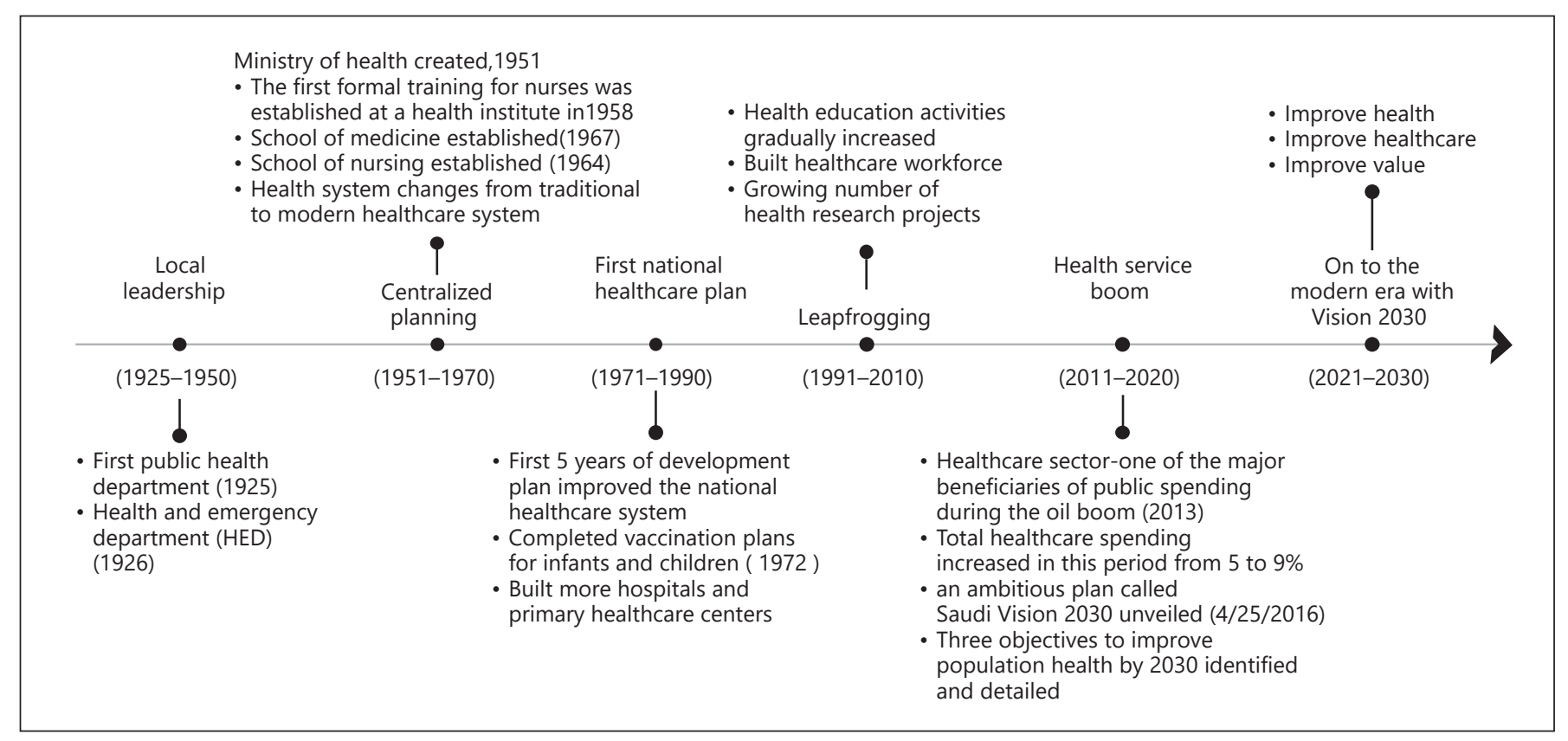

Fig. 1. Evolution of the health system in Saudi Arabia (1925-2030).

Infant Mortality Rate

The number of deaths among infants under 1 year of age during a given time interval divided by the number of live births reported during the same time interval multiplied by 1,000 . The data are adjusted for underreporting of infant deaths and HIV [8].

\section{Maternal Mortality Rate}

The number of deaths assigned to pregnancy-related causes during a given time interval divided by the number of live births during the same time interval multiplied by 100,000 . The data are adjusted for underreporting and misclassification of deaths [9].

\section{GDP per Capita}

This stands for gross domestic product (GDP) per capita [10]. It is derived from the total GDP divided by the population of a particular area. The data are adjusted for the difference between the rate of inflation in the country and the rate of international inflation [10].

Hospital Bed Occupancy Rate

The number of effectively occupied bed days divided by the number of beds available for care multiplied by 365 days, with the ratio multiplied by 100 .

Health Systems Definitions

Here, we briefly explain the definition of WHO's 6 Building Blocks [11].

\section{Service Delivery}

The means by which patients receive individualized treatment and necessary health supplies. Service delivery can be tailored to specific social determinants of health.

The Transformation of Saudi Arabia's Health System and Its Impact
The Health Workforce

Health personnel who provide direct patient care, such as physicians, nurses, pharmacists, and dentists as well as management and support staff.

Health Information System

The collection, storage, management, and transmittal of patient data with the use of electronic medical records to inform clinical care.

Access to Medicines and Technologies

An integral component of health care, medicines must be dispensed with good quality at the right time and place.

Health Systems Financing

The mobilization, accumulation, and allocation of monetary resources that are critical to the functioning of health systems.

Leadership and Governance

The leaders who initiate legislation and policies and those who establish guidelines and accountability to ensure the efficacy of the health system.

\section{Results}

An overview of the Saudi health system transformation is followed by analysis of the impact of health systems on selected health outcomes in the KSA and the USA. 
Transformation of Saudi Arabian Health Systems

Figure 1 shows the evolution of the health systems in the KSA over nearly 10 decades from 1925 to 2020 . The development can be categorized into 5 stages: local leadership (1925-1950), centralized planning (1951-1970), growth (1971-1990), leapfrogging (1991-2010), and health service boom (2011-2020). Looking to the future, service expansion is planned in accordance with Vision 2030 (2021-2030).

\section{Local Leadership (1925-1950)}

The first local public health department was established in Mecca in 1925 by a royal decree from King Abdulaziz [12]. This public health department was initially charged with monitoring population health through the establishment and sponsorship of hospitals and dispensaries. While this was an important first step in providing curative medicine, the allocated resources were not enough to achieve major advances in healthcare [13]. The majority of people continued to depend on traditional medicine, and the incidence of infectious diseases remained high among the population $[12,13]$. In 1926, the Saudi government issued another decree to fund the Health and Emergency Department (HED). The HED was responsible for promoting public and environmental health, establishing hospitals and healthcare centers, managing human resources within these centers, legislating policies and procedures to ensure public safety, and promoting medicine and pharmacology standards [12, 13]. The first school of nursing opened in the same year, followed by the first school of health and emergencies in 1927.

The Saudi MOH, a governing body for the healthcare delivery system, was established in 1951 under the Royal Decree [14], 25 years after the creation of the HED. During the 1950s, preventive services were improved. For example, malaria control and prevention campaigns/programs were introduced through the collaborative efforts of the $\mathrm{MOH}, \mathrm{WHO}$, and Arabian American Oil Company (Aramco) [15].

\section{Centralized Planning (1951-1970)}

Health services expanded in 1951 with the leadership of the MOH. In response to educational needs, school health units were established in 1954 and mainly provided curative services and a few preventative services related to immunization, counseling, and health lectures $[12,13]$. The Ministry of Education accepted only men as pupils, teachers, and employees into these health units, and they were available only in major cities such as Riyadh, Makkah, and Jeddah [12, 13]. During this stage, the healthcare system in the KSA began its transformation from traditional medicine to modern healthcare $[12,13]$.

\section{Growth (1971-1990)}

This period is characterized by economic booms that stimulated the growth of the healthcare system in the KSA [12-16]. Due to the massive oil revenue influx in the 1970s, the government was able to invest in the industrial, agricultural, transportation, communication, education, and healthcare sectors [16]. The aim of the first and second development plans (1970-1979) was to improve the national healthcare system and implement vaccination plans for infants and children. As a result, from 1970 to 2011, the mortality rate was reduced substantially from 250 deaths per 1,000 to 19.1 deaths per 1,000 [16].

The 1980s was a very successful decade for the Saudi healthcare system, during which time the third development plan resulted in the construction of numerous hospitals and primary healthcare centers. During a 2-year period, an impressive total of 377 healthcare facilities were built, of which 65 were hospitals and the rest were primary healthcare centers [13-17]. At the end of the 1980s to the mid-1990s, during the fourth and fifth development plans, oil prices plummeted leading to a relatively flat $\mathrm{MOH}$ budget and a slowdown of the growth of the private healthcare industry $[12,13]$. Since the MOH budget did not allow for price fluctuation, money was allocated primarily for curative care, resulting in fewer resources for preventive care.

\section{Leapfrogging (1991-2010)}

During the 1990s, in order to build the healthcare workforce, the school health units established female schools in rural and urban areas [12-16]. These school health units also expanded their services to promote a healthy lifestyle, including information on nutrition, oral health, personal health/hygiene, smoking cessation, and physical activity through services provided by general physicians, dentists, nurses, and public health professionals [13]. Medical education also expanded in the late 1980s, with 340 doctors and 89 dentists graduating from 5 medical colleges and 2 dental schools in 1998 [18], respectively. Subsequently, a large number of health research projects started in many fields of medicine and health sciences, leading to the creation of 16 Saudi medical journals [18].
Young/Alharthy/Hosler 


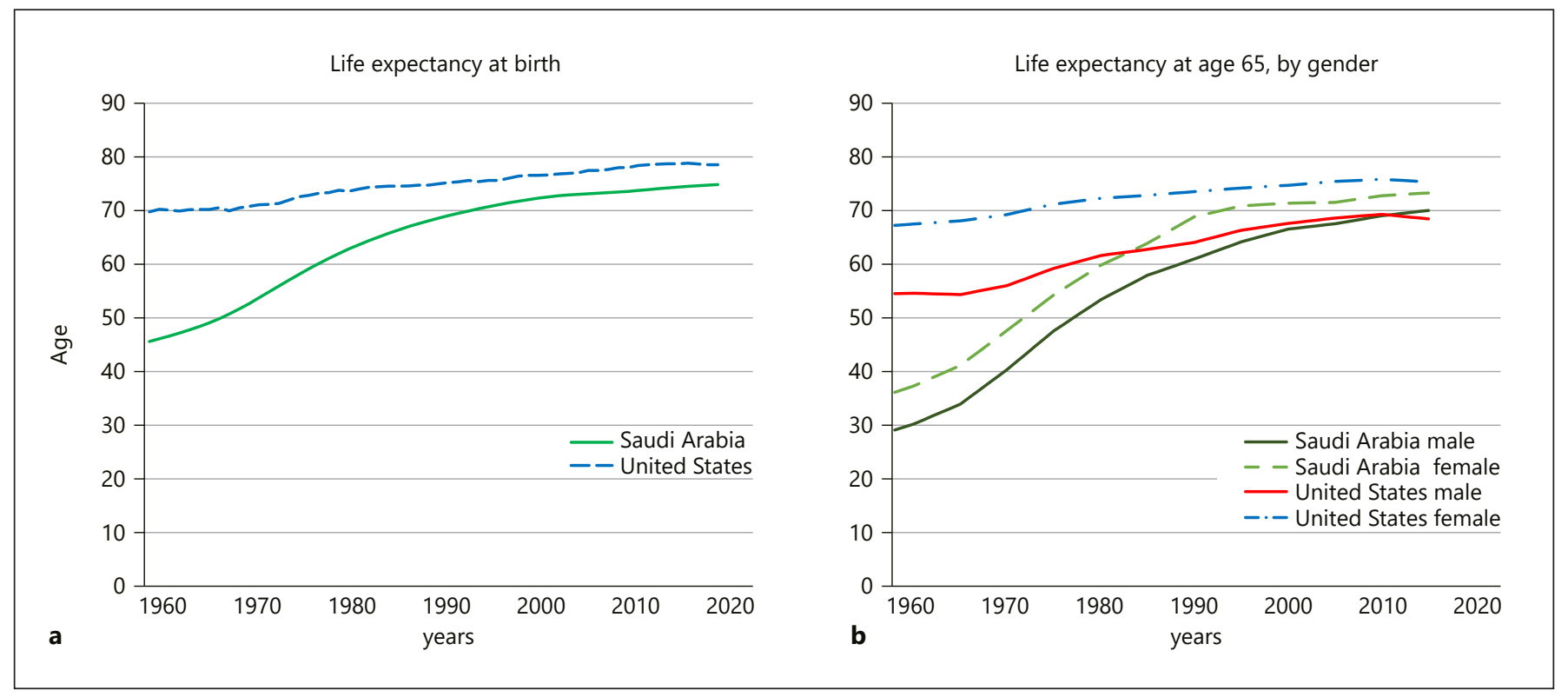

Fig. 2. Comparison of life expectancy at birth and at 65 between Saudi Arabia and the USA (1960-2019). Note: data source can be found in the World Bank Group, Survival to age 65; United Nations Population Division, World Population Prospects: 2019 Re-

vision, The World Bank Data https://data.worldbank.org/indicator/SP.DYN.TO65.FE.ZS; World Health Organization, Global Health Observatory data repository, Life Table by Country-Saudi Arabia https://apps.who.int/gho/data/view.main.61440?lang=en.

Health Service Boom (2011-2020)

The healthcare sector was one of the major beneficiaries of public spending during the oil boom in this period. The total healthcare spending increased by an average of $0.5 \%$ per year from $5 \%$ in 2003 to $9 \%$ in 2018 [14, $18,19]$. In 2014, the healthcare budget reached SAR 84.4 billion (USD 22 million). As a result, the number of hospitals increased from 415 in 2010 to 453 in 2015, and correspondingly, the number of beds increased from 58,126 to 64,694 [20]. On April 25, 2016, the KSA unveiled an ambitious plan called Saudi Vision 2030 to transform its economy by diversifying the sources of income and reducing dependence on oil. In addition, the National Transformation Program (NTP) was enacted as an economic action plan and as part of the Vision 2030 development plan. The NTP aims to improve quality of patient care and provide integrated healthcare matching the highest international standards through an initiative developed by the MOH [21]. The NTP 2020 is the first step toward realization of the Vision 2030. It maps out an economic development process that balances general policies, special targets, and ongoing commitments to become a pioneering model at all levels, including the healthcare system.

The Transformation of Saudi Arabia's Health System and Its Impact

To the Modern Era with Vision 2030 (2021-2030)

The main goal of Vision 2030 is to diversify the economy by reducing its reliance on hydrocarbons (petroleum and natural gas) and encouraging more private participation by encouraging both local and international investments in several key industries such as healthcare [21]. The privatization of government services is expected to meet the goals of Vision 2030 by increasing the private sector's contribution to the GDP from 40 to $65 \%$ by 2030 [21]. The NTP has identified 3 healthcare transformation objectives to be achieved by 2030: (1) increasing access to healthcare services, (2) improving the quality and efficiency of healthcare services, and (3) promoting disease prevention through improved access to care and preventive services [21].

\section{The Impact of Health Systems on Selected Health}

Outcomes in Saudi Arabia and the USA

Table 1 presents selected geographic and population characteristics and health status in the KSA and the USA in 2019. The KSA has a population of approximately 34 million, or about $1 / 10$ of the US population, and less than half the population density compared to the USA. The 2 countries have similar proportions of high school graduates, but the KSA has a much greater proportion of col- 


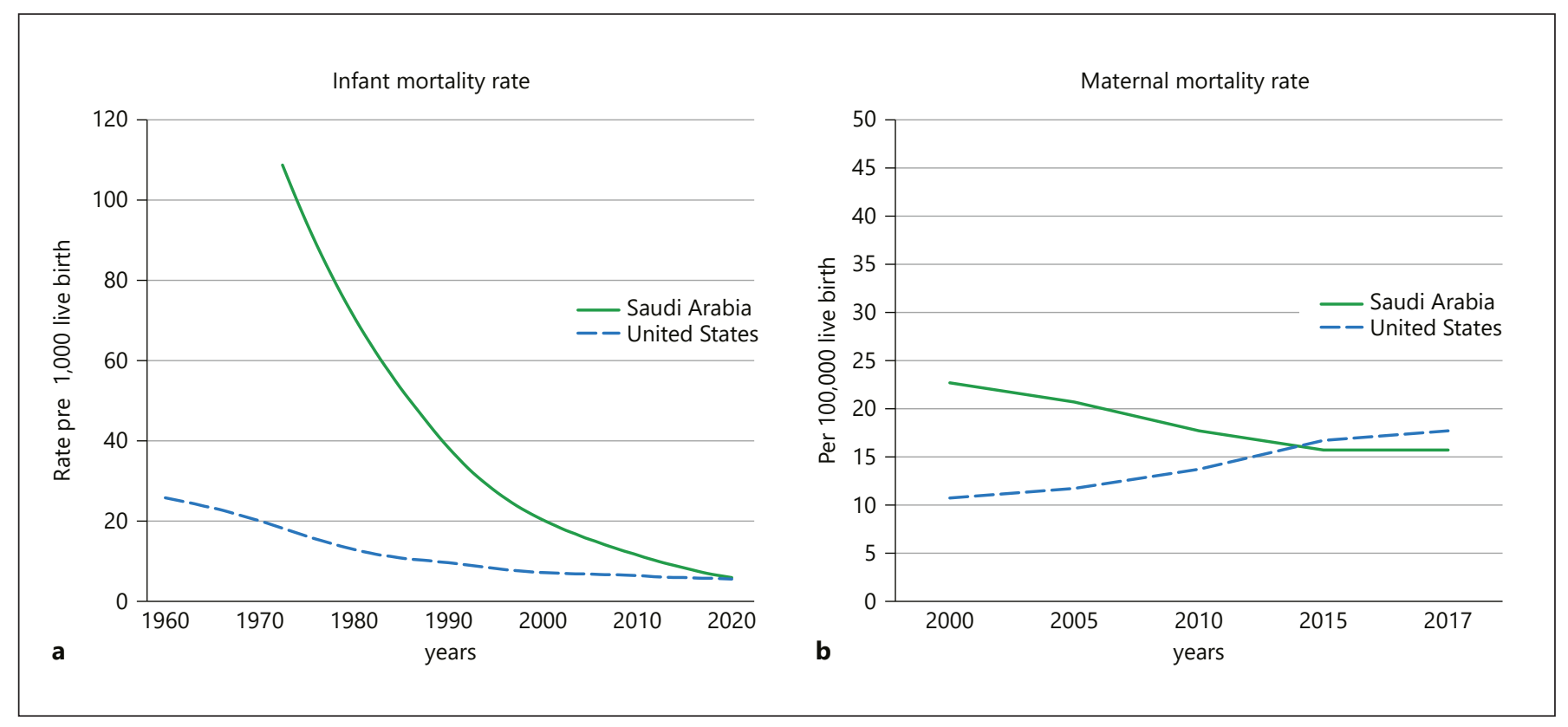

Fig. 3. Comparison of infant and maternal mortality rates between Saudi Arabia and the USA (1960-2019). Note: data source can be found in UNICEF, Maternal mortality data; World Health Organization, The Global Health Observatory, https://www.who.int/ data/gho/data/countries; UNICEF Data: Monitoring the situation

of children and women: Maternal mortality https://data.unicef. org/topic/maternal-health/maternal-mortality/\#; The World Bank Data. Mortality rate, infant (per 1,000 live births) https:// data.worldbank.org/indicator/sp.dyn.imrt.in?view=chart.

lege graduates than the USA (68.6 vs. $37 \%)$ [22, 23]. Health status results show that life expectancy at birth was slightly lower in the KSA (74 years for men and 76 years for women) compared to the USA (76 years for men and 81 years for women). However, the proportion of GDP spent by the Saudi government on health care was half that of the USA ( $9 \%$ compared to $18 \%$ in 2017 , respectively) $[19,24]$. The disparity in spending grew in 2018, with Saudi Arabia spending 9.2\% GDP compared to $18 \%$ GDP in the USA. Despite the spending disparity, health facility and workforce metrics were similar between the KSA and the USA: the number of hospital beds per 10,000 people was 27 versus 29 , respectively, and physicians per 10,000 was 24 versus 26 . In contrast, nurses and midwives were considerably lower in the KSA (57.0 vs. 85.5 per 10,000). Finally, the KSA fared slightly better with respect to a core pediatric health measure: measles vaccination coverage was $98 \%$ in the KSA compared to $92 \%$ in the USA.

Figure 2 depicts a comparison of life expectancy at birth (Fig. 2a) and at age 65 (Fig. 2b) between the KSA and the USA. Life expectancy at birth (Fig. 2a) in both countries has increased over time between 1960 and 2019.

However, it is noticeable that the rate of increase is much faster in the KSA compared to the USA. The life expectancy in the KSA was only 45.6 years in 1960, and it increased to 74.9 years in 2019 , reflecting an impressive increase of 29.2 years over 6 decades. In the USA, the life expectancy increased from 69.8 years in 1960 to 78.5 years in 2019 , with an increase of 8.7 years during the same period. The difference in life expectancy between the 2 countries narrowed considerably, from approximately 29 years in 1960 to < 4 years in 2019.

Life expectancy among older persons of age 65 years or more shows a similar pattern. Generally, life expectancy among seniors is higher in the USA than in the $\mathrm{KSA}$, and when stratified by gender, it is apparent that women's life expectancies in both countries are higher than males (Fig. 2b). Perhaps the most striking change in $65+$ life expectancy was the dramatic improvement among older Saudi males. In 1960, US males over 65 had an excess 25 years' greater life expectancy, but this disparity was eclipsed in 2019 by Saudi males. Among females, the life expectancy gap was also 25 years in 1960, but this gap narrowed and is now similar for both countries. 
Table 1. Comparison on selected sociodemographic and health characteristics between Saudi Arabia and the United States, 2019

\begin{tabular}{|c|c|c|}
\hline Country & $\begin{array}{l}\text { Saudi } \\
\text { Arabia }\end{array}$ & $\begin{array}{l}\text { United } \\
\text { States }\end{array}$ \\
\hline \multicolumn{3}{|l|}{ Population characteristics 1,2} \\
\hline Total population (million) & 34.14 & 327.2 \\
\hline Land area (million mile ${ }^{2}$ ) & 0.830 & 3.797 \\
\hline Population density (people/mile ${ }^{2}$ ) & 41 & 86.2 \\
\hline \multicolumn{3}{|l|}{ Sociodemographic characteristics } \\
\hline Life expectancy at birth (male/female), years & $74 / 76$ & $76 / 81$ \\
\hline Median age (2018), years & 30.3 & 38.2 \\
\hline Sex ratio (male to female) & 1.21 & 0.980 \\
\hline \multicolumn{3}{|l|}{ Education, $\%^{32}$} \\
\hline Completed high school education & 91 & 93 \\
\hline Completed college degree & 68.6 & 37 \\
\hline Literacy & 94.0 & 99.0 \\
\hline \multicolumn{3}{|l|}{ Health budget } \\
\hline GDP, USD (in billion) & 786,522 & 20,494 \\
\hline GDP health expenditure, USD (in billion) & 9.2 & 18.0 \\
\hline \multicolumn{3}{|l|}{ Health facility and workforce } \\
\hline Hospital beds (per 10,000 people) & 27.0 & 29.0 \\
\hline Physicians (per 10,000 people) & 24.0 & 26.0 \\
\hline Nurses and midwives (per 10,000 people) & 57.0 & 85.5 \\
\hline \multicolumn{3}{|l|}{ Vaccination by 2 years, $\%^{5}$} \\
\hline DTP (Diphtheria/tetanus/pertussis) & 98.0 & 95.0 \\
\hline Measles & 98.0 & 92.0 \\
\hline Haemophilus influenzae b (Hib) & 98.0 & 93.0 \\
\hline \multicolumn{3}{|l|}{ Chronic conditions, $\%$} \\
\hline Heart disease ${ }^{24}$ & 5.5 & 11.5 \\
\hline Hypertension & 48.4 & 32.1 \\
\hline Stroke $e^{23}$ & 1.9 & 3.0 \\
\hline Diabetes & 7.8 & 9.4 \\
\hline Obesity & 52.9 & 39.8 \\
\hline
\end{tabular}

Superscripts 1, 2, 5, 23, 24, and 32 indicate references.

Figures $3 \mathrm{a}$ and $\mathrm{b}$ show the comparison of infant and maternal mortality rates between the KSA and the USA. As depicted in Figure 3a, the Saudi infant mortality rate had a considerable drop from over 100 per 1,000 live births in 1970 to 2 per 1,000 live births in 2019. Although the USA started in a much better position, the infant mortality rate also declined to 2 per 1,000 live births in 2019 as well. Figure $3 \mathrm{~b}$ shows the maternal mortality rate comparison for the period between 2000 and 2017. In the KSA, the maternal mortality rate steadily decreased from 25 per 100,000 live births in 2000 to 17 per 100,000 live births in 2017. In comparison, the USA experienced a doubling in the maternal mortality rate, from 10 per 100,000 live birth to 23 per 100,000 live births during the same period. In fact, by 2015 , the maternal mortality rate in the USA was worse than in the KSA.

The Transformation of Saudi Arabia's Health System and Its Impact

\section{Discussion}

\section{Evaluation of the Current State of Saudi Health}

Systems Using the WHO's 6 Building Blocks

Service Delivery

There are 6 dimensions of service delivery in the healthcare system defined by the WHO including quality of care, accessibility, coverage, continuity, coordination, accountability, and efficiency. In this study, we will focus on accessibility and coverage. In these dimensions, the Saudi government provides universal health care, which allows all Saudi citizens and noncitizens with legal documents free access to comprehensive healthcare coverage. The USA has a multipayer health insurance system, a combination of private and government-sponsored public insurance plans with no universal coverage. Accessibility and coverage depend on health insurance status in the USA. According to a WHO report [25], countries with universal coverage show better overall population health outcomes. A recent study of health trends in 153 countries found that universal coverage, in general, leads to better access to essential care and increased population health with the largest gains accruing among the poor [25, $26]$. This evidence is consistent with the greater net increase in life expectancies and greater improvements in maternal and child health outcomes in the KSA compared to the USA.

\section{The Health Workforce}

In the KSA, there is a shortage of primary care physicians, specialist physicians, nurses, pharmacies, and administration staff, especially in small cities. In the USA, there are adequate numbers of medical specialists, but there is a shortage of primary care nurses, pharmacists, and administration staff, especially in rural areas [27]. In the KSA, the proportions of dentists, pharmacists, and nurses are $5.0,8.7$, and 55.2 per 10,000 population compared to $6.1,10.5$, and 85.5 per 10,000 population in the USA $[12,28]$. In general, rural versus urban area disparities in the health workforce are concerns for both countries.

\section{Health Information System}

In January 2008, the Saudi Health Council approved the unified electronic health file project. In 2011, the $\mathrm{MOH}$ appointed an Information and Communication Technology (ICT) team and developed a 10-year ehealth strategic plan to improve the Saudi healthcare system and its services [19]. Between 2011 and 2019, $39 \%$ of $\mathrm{MOH}$ hospitals used HIS, whereas $61 \%$ of pri- 
mary health care centers did not have access to HIS [19]. Not surprisingly, large government hospitals are more likely to use HIS; for instance, $96 \%$ of King Faisal Hospital (KFH) departments have adopted an e-health system [27]. Use of HIS in private hospitals is largely dependent on the size, as measured by the number of beds; however, data on HIS adoption rates among private hospitals are scarce.

In contrast, the USA demonstrated a high adoption rate of health IT by 2017 , with $96 \%$ of all nonfederal acute care hospitals reporting certified health IT systems in use [27]. Small rural and critical access hospitals had the lowest rates at $93 \%$. When stratified by size, $99 \%$ of large hospitals (>300 beds) had certified health IT, with mediumsized hospitals (100-299 beds) close behind at 97\% [27]. A 2016 report from the American Hospital Association (AHA) showed that patient portal adoption had reached 92\% [27]. However, due to the decentralized multipayer system, meaningful integration is slow to develop despite the financial incentives encouraging interoperability. More widespread, meaningful health information exchange will enable healthcare providers and patients to securely access patients' medical information and facilitate timely treatment decisions, leading to higher quality patient care.

It is expected that HIS will continue to be more fully integrated into the Saudi health system as it is delineated in the National Transformation Program. As seen in Figure 1, with Vision 2030, the KSA will improve the quality of healthcare through building a universal HIS that will link all hospitals and primary care facilities. HIS is a technological means to achieve organized and coordinated treatment processes, optimized patient outcomes, minimized operational expenses, and improved patient satisfaction.

\section{Access to Medicines and Technologies}

In the KSA, all citizens receive medicines free of charge at all governmental healthcare facilities. Additionally, the public health and social health insurance systems provide free medicines for certain conditions. For instance, the public health service provides coverage for medicines that are on the Saudi National Formulary for inpatients and outpatients. Under the Saudi law, there are no restrictions on medication benefits; in other words, citizens have the right to access medications. Private health insurance plans also provide medication coverage. They are required to provide at least partial coverage for medications that are on the Saudi National Formulary. In the USA, patients can access health insurance coverage from a va- riety of sources, such as an employer-sponsored health plan, a health insurance exchange plan, or a public program like Medicare or Medicaid. The literature suggests that government-sponsored free access to medication yields better health outcomes among populations [26], a correlation which may explain the improved life expectancy and lower infant and maternal mortality rates in the KSA compared to the USA.

\section{Health Systems Financing}

In the KSA, the healthcare system is supported by the oil revenues of the Saudi government, with the exception of private hospitals where patients must pay outof-pocket to receive service. The KSA government spends $9.2 \%$ of its GDP budget on health systems financing (Table 1) $[29,30]$. In the USA, the health care system is financed by public taxes and private financing through insurance premiums, copayments, deductibles, and co-insurance. Health spending in the USA is $18 \%$ of the US GDP, nearly 3 times greater than in the KSA. This disparity in expenditure may be attributable to higher adoption and use of advanced technology, some of which may be unnecessary, and a complex pricing system [31].

\section{Leadership and Governance}

In the KSA, leadership and governance are centralized. Following the guidance of the King and Crown Prince, the regional health authorities take responsibility for strategic planning, policymaking, and supervising the delivery of services. The legislative process and chain of command is much simpler in the KSA compared to the USA. For example, laws and policies are drafted by the Saudi Health Council, and the MOH submits them to the Cabinet for final approval by the King and the Crown Prince. In the USA, in contrast, leadership and governance are more decentralized, and as such, the process of creating and implementing laws and policies is complex. Lobbyists and stakeholders may influence legislative decisionmaking, which may delay the progress of healthcare reform. The Saudi system lends itself to faster pivots in health policy. For example, during the 1960s, the Saudi government chose to reduce infant mortality, and the MOH immediately implemented 2 interventions: (1) a public awareness campaign about vaccinations and (2) access to free vaccination for the public through hospitals and schools. These fast actions resulted in a dramatic reduction of infant mortality rates to parity with the USA $[12,13]$. 


\section{Conclusion}

Overall, the KSA has attained remarkable health outcomes in the past few decades. In comparison with the USA, the KSA spends a third of what the USA spends on healthcare and has a markedly smaller health workforce, with a fledging HIS; nevertheless, the KSA now has life expectancy and infant mortality rates on par with the USA, with a lower maternal mortality rate. These remarkable achievements in health outcomes may be attributable to the KSA's universal health insurance and free access to medicine/diagnostic technology, a conclusion which draws support from the literature: countries with universal health insurance tend to have better overall population health, especially among the poor [26].

In contrast, the USA spends about $17 \%$ of its GDP on healthcare, but a significant portion of the population remains uninsured. Before the introduction of the Affordable Care Act in 2013, 13\% of Americans (46 million) were uninsured. With expanded access to insurance for nonelderly Americans, the proportion of uninsured decreased to $8.5 \%$ (27 million) [32]. Accessibility to needed healthcare, treatments, and diagnostic technologies in the USA depends on whether one has health insurance. Healthcare in the USA is very expensive, and those who cannot afford health insurance have reduced access to healthcare. Further, the complex American political system and polarized social values continue to pose barriers toward implementation of a universal health insurance system. At the same time, efforts have been undertaken by both public and private payers to contain health spending and improve preventive health.

With respect to the future of health systems in both countries, the USA will continue to weigh policies to expand coverage while containing spending, and the KSA will likely continue to increase adoption of HIS and expand its health workforce and facilities, especially in rural areas. Advantageous to the Saudi health system is its established policy of universal coverage and efficient leadership. The KSA is on par with an established industrialized nation on selected health outcomes. This analysis demonstrates the impact of dramatic changes in health system financing and delivery on key population health metrics, such as life expectancy and infant and maternal mortality. Future research should explore the degree to which health reforms in the USA predicated on reducing the disparities in health care access which may be driving US health statistics down in comparison with the KSA.

\section{Acknowledgment}

The authors gratefully acknowledge the editorial contributions of Allison Krug, MPH.

\section{Statement of Ethics}

This study used de-identified, publicly available data, and it does not require IRB approval.

\section{Conflict of Interest Statement}

The authors have no conflicts of interest to declare.

\section{Funding Sources}

There was no sponsor for this study.

\section{Author Contributions}

This study has not been published before, nor is it being considered for publication elsewhere. All authors meet the criteria for authorship stated in the Uniform Requirements for Manuscripts Submitted to Biomedical Journals. The authors worked individually and collaboratively on this study. Young initiated the project, provided the conceptual framework, interpreted the results, structured the Discussion section, and critically reviewed and revised the manuscript. Alharthy contributed to the concept development, conducted literature search, obtained and organized the data, and drafted the manuscript. Hosler reviewed the manuscript and offered critical feedback. The authors met frequently to discuss the project throughout the process. Young gave the final approval of the version to be published.

\section{References}

The Transformation of Saudi Arabia's Health System and Its Impact
1 OPAC Organization. Saudi Arabia: OPEC; 2019. Available from: https://www.opec.org/ opec_web/en/about_us/169.htm Accessed $2021 \mathrm{Feb} 6$.

2 Saudiembassy Net. Islam: The Embassy of the Kingdom of Saudi Arabia; 2019. Available from: www.saudiembassy.net/islam Accessed $2021 \mathrm{Feb} 6$.
3 Almalki M, Fitzgerald G, Clark M. Health care system in Saudi Arabia: an overview. East Mediterr Health J. 2011;17(10):784-93.

4 Albejaidi FM. Healthcare system in Saudi Arabia: an analysis of structure, total quality management and future challenges. J Alt Perspect Soc Sci. 2010;2(2):794-818. 
5 Walston S, Al-Harbi Y, Al-Omar B. The changing face of healthcare in Saudi Arabia. Ann Saudi Med. 2008;28(4):243-50.

6 Saad Alsumaih I, Abdulaziz Aldhuwayhi F. Characteristics of medical services in the US versus Saudi Arabia. Sci J Public Health. 2015; 3(4):588.

7 WHO. WHO methods and data sources for life tables 1990-2016. 2019. Available from: https: //www.who.int/healthinfo/statistics/ LT_method.pdf?ua=1 Accessed 2021 Feb 6 .

8 WHO. Estimation method for child mortality used in: level and trends of child mortality -report 2013 estimates developed by the WHO, UNICEF, UN population division and World Bank consultation. 2019. Available from: https: //www.who.int/gho/child_health/mortality/ChildCME_method.pdf Accessed 2021 Feb 6.

9 WHO. Indicator metadata registry details. 2019. Available from: https://www.who.int/ data/gho/indicator-metadata-registry/imrdetails/26 Accessed 2021 Feb 6.

10 Worldbank Organization. Glossary DataBank. databank.worldbank.org. Available from: https: //databank.worldbank.org/metadataglossary/ world-development-indicators/series/NY.GDP. PCAP.KN\#: : text=GDP\%20per\%20capita\%20 is\%20gross Accessed $2021 \mathrm{Feb} 6$

11 WHO. Monitoring the building block of health systems: a handbook of indicators and their measurement strategies. 2019. Available from: https://www.who.int/healthinfo/systems/WHO_MBHSS_2010_full_web.pdf Accessed 2021 Feb 6.

12 Al-Harthi F. Health over a century. Riyadh, Saudi Arabia: Ministry of Health; 1999.

13 Al-Hashem A. Health education in Saudi Arabia: historical overview. Sultan Qaboos Univ Med J. 2016;16(3):e286-92.
14 Saudi Arabia Ministry of Health. About the ministry. Available from: www.moh.gov.sa/ en/Ministry/About/Pages/default.aspx Accessed 2021 Feb 6.

15 Al-Yousuf M, Akerele TM, Al-Mazrou YY. Organization of the Saudi health system. East Mediterr Health J. 2002 Jul-Sep;8(4-5):64553.

16 Aldossary A, While A, Barriball L. Health care and nursing in Saudi Arabia. Int Nurs Rev. 2008;55:125-8.

17 Khaliq AA. The Saudi health care system: a view from the minaret. World Health Popul. 2012;13:52-64.

18 Saudi Arabia Ministry of Health. Statistical yearbook. 2014. Available from: www.moh. gov.sa/Ministry/Statistics/book/Pages/default.aspx Accessed 2021 Feb 6.

19 Saudi Arabia Ministry of Health, Health 2019. Available from: https://www.keyworddensitychecker.com/search/himss19-pdf Accessed $2021 \mathrm{Feb} 6$.

20 Al-Hanawi MK, Khan SA, Al-Borie HM. Healthcare human resource development in Saudi Arabia: emerging challenges and opportunities-a critical review. Public Health Rev. 2019;40:1.

21 Vision2030. National transformation program. 2019. Available from: https://www.vision2030.gov.sa/sites/default/files/attachments/NTP\%20English\%20Public\%20Document_2810.pdf Accessed 2021 Feb 6.

22 Saudi Arabia UNESCO UIS. Unesco.org. Published 2019. Available from: http://uis. unesco.org/en/country/sa Accessed $2021 \mathrm{Feb}$

23 US Census Bureau. U.S. Census Bureau releases new educational attainment data. The United States Census Bureau. Available from: https://www.census.gov/newsroom/press-releases/2020/educationalattainment.html\#: : t ext $=$ In \% $202019 \% 2 \mathrm{C} \% 20 \mathrm{high} \% 20$ school\%20was Accessed 2021 Feb 6.
24 CDC data finder: health, United States: products. www.cdc.gov. Published 31 Mar 2020. Available from: https://www.cdc.gov/nchs/ data/hus/2018/042.pdf Accessed 2021 Feb 6.

25 Moreno-Serra R, Smith PC. Does progress towards universal health coverage improve population health? Lancet. 2012;380:917-23.

26 Moreno-Serra R, Smith PC. Does progress towards universal health coverage improve population health? Lancet. 2012;380:917-23.

27 American Hospital Association. AHA Data products. AHA; 2020. Available from: https: //www.aha.org/data-insights/aha-data-products Accessed 2021 Feb 6

28 WHO. GHO: by indicator. Hospital beds (per 10000 population) (Global Dementia Observatory (GDO)). 2019. Available from: http:// apps.who.int/gho/data/node.imr.WHS6_102 Accessed 2021 Feb 6.

29 Memon I, Abu-Shaheen A, Heena H, Al-Tannir M. Point prevalence study for stroke in Saudi Arabia: a cross-sectional survey. Saudi J Health Sci. 2019 [cited 2019 Dec 6];8:93. http: //www.saudijhealthsci.org/text.asp?2019/ 8/2/93/261539.

30 Kalaf H, AlMesned A, Soomro T, Lasheen W, Ewid M, Al-Mohaimeed AA. Cardiovascular disease risk profile among young Saudi women of Al-Qassim, Saudi Arabia: a cross-sectional study. Int J Health Sci. 2016;10(1):2937.

31 Mills MD. Why is health care so expensive in the United States? J Appl Clin Med Phys. 2016;17(3):1-4. Published 2016 May 8.

32 US Census Bureau. Health insurance coverage in the United States: 2018. The United States Census Bureau. Available from: https: // www.census.gov/library/publications/2019/demo/p60-267.html Accessed 2021 Feb 6 